\section{LEUKAEMIA AND PREgNANCY}

BY

\section{JAMES ALLAN, M.B., B.Sc., F.R.F.P.S.} Senior Registrar, Western Infirmary, Glasgow

The occurrence of pregnancy in women suffering from leukaemia or the onset of this disease during pregnancy is rare, and in the latter instance the diagnosis may be overlooked. Leukaemia itself is not a common condition. During 1948 it was responsible for only $1.6 \%$ of all malignant growths in Scotland (RegistrarGeneral, 1948). The figures for England and Wales were almost identical. When only 95 cases, sufficiently documented, can be collected from the world literature it will be appreciated that few of us are likely to have personal experience of a significant number of patients. Knowledge of the subject has therefore to be derived from analytical reviews of small series of cases.

Grier and Richter (1939) were able to collect references to 75 cases of pregnancy and leukaemia In a later and more extensive review of the world literature McGoldrick and Lapp (1943) collected references to 111 cases, in only 75 of which was the diagnosis sufficiently substantiated. They added one case of their own. The cases were classified according to the results of blood examination into acute and chronic types, as in Tables I and II. Of 31 cases of acute leukaemia in McGoldrick and Lapp's series, 17 were myelogenous, 9 lymphogenous, and 2 haemocytoblastic; 3 were unclassified. Chronic leukaemia accounted for 45 cases -42 myelogenous and 3 lymphogenous. Williams (1948) traced eight additional cases and described two cases personally known to him, one of which was of acute monocytic type and which was claimed by him to be the only instance of this variety recorded. His series included three cases of acute leukaemia-one lymphatic, one myeloid, and one monocytic-and seven cases of chronic myeloid type; whilst
Li et al. (1947) recorded four cases of the chronic myeloid variety. Edwards and Freeth (1950) reported one case of chronic myeloid leukaemia.

Having had experience of one case (Case 1), I was prompted to search the records for the past twenty years of a general hospital and of a principal maternity hospital. Details of a further three cases were traced. In view of the relatively small number of cases reported in the literature and of the problems involved, it seems justifiable to record the details of these four cases.

\section{Case Reports}

Case 1.-A 4-para aged 25 was admitted to hospital in January, 1948, complaining of shortness of breath and swelling of the abdomen for eight months. Amenorrhoea had been present for three years. The spleen was enlarged. Blood examination revealed : $\mathrm{Hb}, 65 \%$ Sahli $(9.1 \mathrm{~g} . \%)$; red cells, 3,400,000 per c.mm. ; white cells, 223,000 per c.mm. (blast cells $1 \%$, myelocytes $44 \%$, polymorphs $55 \%$ ). A diagnosis of chronic myeloid leukaemia was made. Treatment with urethane orally was given up to a total dosage of 199 g., after which her white-cell count had fallen to 12,000 while the differential count revealed no blast cells and only $5.5 \%$ myelocytes. She was discharged from hospital feeling well. Nine months later she was admitted to a maternity hospital complaining of vaginal bleeding, and was found to have a full-time pregnancy, complicated by lateral placenta praevia and severe ante-partum haemorrhage. She was delivered of a full-time mature stillborn male child. Her white-cell count was now 350,000 . During the postpartum period she required 8 pints $(4.5$ litres) of blood to counteract haemorrhage. The spleen was enlarged down to the umbilicus, blast cells were present in the peripheral blood, and myelocytes constituted $49 \%$ of the white blood cells. A second course of urethane was given orally, and after a total dosage of $51 \mathrm{~g}$. the white-cell count fell to 20,000 . She remained well for six months, by which time the white cells had increased to 380,000 . The leukaemia then failed to respond to treatment and she died shortly afterwards.

Case 2.-A 2-para aged 23 was admitted to hospital in July, 1937, with a diagnosis of anaemia and splenomegaly.

TABle I.-Summary of 34 Cases of Acute Leukaemia Associated with Pregnancy

\begin{tabular}{|c|c|c|c|c|c|c|c|c|c|c|c|c|c|c|}
\hline & \multicolumn{3}{|c|}{ Leukaemia } & \multicolumn{4}{|c|}{ Pregnancy } & \multicolumn{4}{|c|}{ Maternal Deaths } & \multicolumn{3}{|c|}{ Foetal Deaths } \\
\hline & \multirow{2}{*}{$\begin{array}{l}\text { Mye- } \\
\text { loid }\end{array}$} & \multirow{2}{*}{$\underset{\text { atic }}{\text { Lymph- }}$} & \multirow{2}{*}{ Others } & \multicolumn{2}{|c|}{ Diagnosed } & \multirow{2}{*}{$\begin{array}{c}\text { Full } \\
\text { Time }\end{array}$} & \multirow{2}{*}{$\begin{array}{c}\text { Pre- } \\
\text { mature }\end{array}$} & \multirow{2}{*}{$\begin{array}{l}\text { During } \\
\text { Prog- } \\
\text { nancy }\end{array}$} & \multirow{2}{*}{$\begin{array}{l}\text { During } \\
\text { Partu- } \\
\text { rition }\end{array}$} & \multirow{2}{*}{$\begin{array}{c}\text { Post- } \\
\text { partum }\end{array}$} & \multirow{2}{*}{ Total } & \multirow{2}{*}{$\begin{array}{l}\text { Still- } \\
\text { born }\end{array}$} & \multirow{2}{*}{$\begin{array}{c}\text { Pre- } \\
\text { mature }\end{array}$} & \multirow{2}{*}{ Total } \\
\hline & & & & Before & During & & & & & & & & & \\
\hline $\begin{array}{l}\text { McGoldrick and } \\
\text { Lapp's review (1943) } \\
\text { Williams (1948) }\end{array}$ & $\begin{array}{r}17 \\
1\end{array}$ & $\begin{array}{l}9 \\
1\end{array}$ & $\begin{array}{l}5 \\
1\end{array}$ & $\underline{2}$ & $\begin{array}{r}29 \\
3\end{array}$ & $\begin{array}{l}9^{*} \\
1\end{array}$ & $11^{*}$ & 4 & 5 & $\begin{array}{r}22 \\
3\end{array}$ & $\begin{array}{l}100 \\
100\end{array}$ & $\begin{array}{l}9 \\
1\end{array}$ & -3 & $\begin{array}{l}60 \dagger \\
33 \cdot 3\end{array}$ \\
\hline & 18 & 10 & 6 & 2 & 32 & 10 & 12 & 4 & 5 & 25 & & 10 & 3 & \\
\hline
\end{tabular}

* Includes only non-interrupted pregnancies. † Excludes those embryos not surviving to the stage of viability.

TABLE II.-Summary of 61 Cases of Chronic Leukaemia Associated with Pregnancy

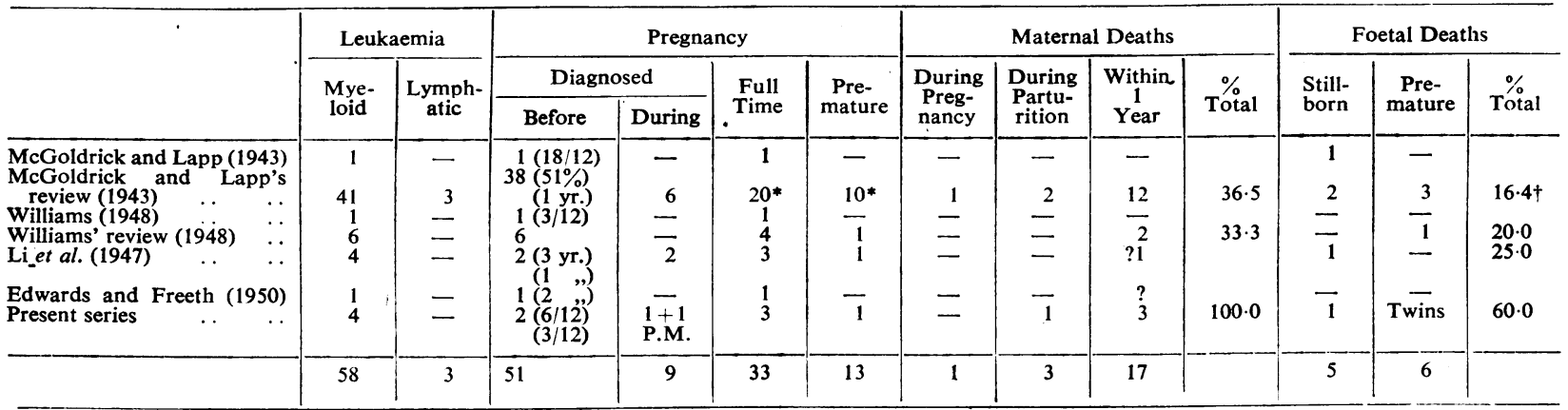

* Includes only non-interrupted pregnancies. 
Examination of her blood revealed: $\mathrm{Hb}, 45 \%$ (Sahli); red cells, $3,010,000$ per c.mm. ; white cells, 580,000 per c.mm. Chronic myeloid leukaemia was diagnosed, and she was given a course of $x$-ray treatment, applied to the spleen. Over a period of three months, 1,700 $\mathrm{r}$ skin doses reduced the white-cell count to 23,000 , and the spleen was no longer palpable. She was discharged from hospital feeling well. One year later she was found to be six months pregnant. Her last pregnancy had been three years previously. She was feeling well and her white-cell count was 44,000. She was delivered of a live full-time female child weighing $6 \mathrm{lb}$. $(2.7 \mathrm{~kg}$.). Haemorrhage was slight and the third stage of labour normal. The white blood cells then numbered 174,000 . She developed a progressive anaemia and died in coma twenty-five days after delivery. Necropsy confirmed the diagnosis of chronic myeloid leukaemia.

Case 3.-A housewife aged 27 was referred to a maternity hospital during her second pregnancy in June, 1949, as her abdomen seemed larger than her 33 weeks' maturity would suggest. One year previously she aborted after eight weeks' gestation. A vertex presentation was confirmed, but her spleen was also felt to be enlarged, and examination of her blood revealed chronic myeloid leukaemia. The white-cell count was 200,000 per c.mm.; Hb, $53 \%$ Sahli (7.4 g. \%); and red cells $3,700,000$ per c.mm. Labour began four weeks later, a forceps delivery being necessary. Brisk haemorrhage occurred, and despite blood transfusion she died seven hours later. The child was full-time, alive, and healthy. Necropsy proved the cause of death to be pulmonary thrombosis, and chronic myeloid leukaemia was confirmed.

Case 4.-A 9-para aged 33 was admitted to a maternity hospital in November, 1934, complaining of frequency of micturition. She was 33 weeks pregnant. Her previous pregnancy had been in 1932. Blood examination revealed: $\mathrm{Hb}, 41 \%$; red cells, $3,300,000$ per c.mm. There was no record of her white-cell count. Two days later she delivered herself of premature twin boys, who died shortly afterwards. Labour was short and easy, but four days later the patient, after a transfusion of blood, became comatose and died. Necropsy revealed splenomegaly and hepatomegaly, and further examination showed the presence of chronic myeloid leukaemia. Bilateral pyelonephritis was also present.

\section{Discussion}

In discussing the problem of leukaemia and pregnancy, it is desirable to consider separately the acute and chronic forms of the disease. Tables I and II have therefore been prepared to facilitate comparison and clarify the issues involved.

Chronic myeloid leukaemia has the highest incidence of all the leukaemias during the child-bearing period, and is thus the type most often associated with pregnancy. It was responsible for $61 \%$ of the total of 95 cases now under review, including four cases reported above. As regards the relationship of leukaemia to parity, the acute type occurs mostly in primiparae, whereas the converse is found in the chronic type.

\section{Effect of Leukaemia on the Gravid Woman}

Acute Leukaemia.-In a total of 34 cases of acute leukaemia complicating pregnancy, only two were diagnosed before pregnancy began; the remainder were diagnosed mostly at seven months' gestation. The maternal mortality was $100 \%$. This is not surprising, as the average life expectancy after the onset of acute leukaemia is stated to be from four to eight weeks (Whitby and Britton, 1946). Four patients died during pregnancy, five during parturition, and the remainder in the post-partum period; few survived longer than fourteen days. Post-partum haemorrhage was severe in five cases and fatal in two. Death was due to the direct effect of acute leukaemia in the other cases.

Chronic Leukaemia.-With regard to the 61 cases of chronic leukaemia, Cases 1 and 2 were diagnosed before the onset of pregnancy, as were $83.6 \%$ of the reviewed cases, while in the remainder, with one exception, the diagnosis was made during pregnancy. Case 3 was diagnosed after reference to hospital as a possible obstetrical abnormality ; it was only when an enlarged spleen was palpated, in addition to a uterus of 33 weeks' gestation, that full blood examination was prompted and the diagnosis became clear. Case 4 demonstrates that it is not always easy to detect splenomegaly in the presence of a gravid uterus nearing its full-time size. Splenomegaly and leukaemia were not discovered until necropsy. Judging from the literature, this diagnostic difficulty does not seem to have been given any prominence.

In cases associated with chronic leukaemia one death occurred during pregnancy, three during parturition, and 17 were confirmed within one year of delivery. McGoldrick and Lapp (1943) found a maternal mortality of $36.5 \%$. Excluding their series, the mortality of the remainder of the cases was $37.5 \%$. Survival for a period of six months was attained in only one instance in my series (Case 1), and antileukaemic treatment was necessary to sustain reasonable health.

When pregnancy was not interrupted by election, and excluding abortions, there were 13 premature labours and 33 full-time gestations. This agrees with my experience in the present series. Apart from a variable degree of anaemia and swelling of the ankles, chronic leukaemia does not seem to complicate maternal health to a gross extent. Severe haemorrhage was recorded in four cases and was fatal in only one instance. In Case 1 placenta praevia was responsible for severe blood loss.

\section{Effect on the Foetus}

Acute Leukaemia.-McGoldrick and Lapp's series of 31 acute leukaemias yielded a foetal mortality of $60 \%$. They stated that stillbirths were an important cause of the high mortality, but did not record a figure. In 23 acute cases sufficiently documented there were 13 foetal deaths, 10 being stillborn and 3 neonatal. Stillbirths were therefore responsible for $76.9 \%$ of the foetal mortality.

Chronic Leukaemia.-In chronic leukaemia, McGoldrick and Lapp quoted a foetal mortality of $16.4 \%$. From the data they produced it is not possible to check this figure or to state the percentage for stillbirths or prematurity. Excluding the 41 cases of their review, and one abortion and one caesarean section reported by Williams (1948), of the remaining 15 cases of non-interrupted pregnancies, there were 3 stillborn, 3 premature (including twins of Case 4), and 10 live children. The foetal mortality rate is therefore $37.5 \%$, and stillbirths and prematurity are each responsible for $50 \%$ of the mortality. Precautions directed to the factors known to be responsible for premature onset of labour may be expected to reduce the foetal mortality. McGoldrick and Lapp did not mention the incidence of abortion, either spontaneous or therapeutic. Excluding their series, but including their own case, there was one abortion in 16 chronic leukaemias, or $6.2 \%$.

All authors are agreed that there is no evidence that leukaemia can be transmitted from mother to foetus. The placenta seems to act as an insuperable barrier to the leukaemic process.

\section{Effect of Pregnancy on Leukaemia}

Does pregnancy have a harmful effect on the course of leukaemia? As regards acute leukaemia, this runs its usual short course, and it cannot be said that pregnancy particularly accelerates the fatal issue. With chronic leukaemia it is difficult to give a precise answer. Because of the insidious onset it is hardly possible to state accurately when the disease first starts, and hence it is difficult to give figures for any possible effect pregnancy may have on its natural progress. The prognosis also depends on whether or not antileukaemic treatment is given, and on its success. The average duration of life, following the onset of symptoms in 259 cases of chronic myeloid leukaemia, uncomplicated by pregnancy, as reported by various writers and quoted by Wintrobe (1951), is 3.28 years. Only $\mathrm{Li}$ et al. (19.47) give 
figures from which it can be stated that two cases had chronic myeloid leukaemia for over three years, during which time pregnancy occurred. McGoldrick and Lapp found that $51.3 \%$ of cases had had chronic leukaemia for one year before the onset of pregnancy. Edwards and Freeth's (1950) patient had been known to be leukaemic two years before her pregnancy, but it is not reported how long she lived afterwards. The course of the leukaemia from onset to death in Cases 1 and 2 can only be estimated as two and a half years, and in Case 3 as two years.

Hofstein (1931) favours the theory that the prognosis for the mother becomes more unfavourable with each successive pregnancy, and that in the later stages of chronic leukaemia pregnancy is not well tolerated and should be terminated. If pregnancy occurs during the first two years of chronic leukaemia, he feels that there is a good chance of delivery at term without danger to the mother. Taussig (1936) states that in acute leukaemia there is little to be gained by termination of pregnancy and that it is hardly, if ever, justified, except in terminal cases in which the possibility of securing a viable child presents itself. Williams (1948) employed caesarean section in one case of chronic and one case of acute leukaemia with survival of the mothers and offspring. McGoldrick and Lapp came to the conclusion that most cases stand parturition well, only to collapse shortly afterwards, but that in many cases the course of the leukaemia is not greatly, if at all, affected by pregnancy. In some cases there is an acute exacerbation of the leukaemia. Cases 1 and 2 seem to belong to this category. In Case 1 the white-cell count increased from 12,000 to 350,000 per c.mm during the course of pregnancy and myeloblasts had reappeared, while myelocytes had increased from $5.5 \%$ to $49 \%$. Megaloblasts were also noted in the peripheral blood, a finding previously reported by Stone (1950). In Case 2 the white-cell count had risen from 44,000 per c.mm. at the sixth month of gestation to 174,000 per c.mm. at parturition, during which blood loss was small, yet death occurred twenty-five days later owing to severe anaemia, despite blood transfusion.

\section{Leukaemia and Multiparity}

The occurrence of two successive pregnancies during the course of a leukaemia is rare. For obvious reasons it does not arise in acute leukaemia. Cameron (1890) and others have reported cases of two pregnancies in the course of chronic leukaemia, despite the fact that necropsies have often shown leukaemic infiltrations of the ovaries and uterus. In a case reported by Williams (1948) the patient conceived a second time one year after the termination of her first gestation. Cases 1 and 3 were probably pregnant twice during the course of their disease; their previous pregnancies had terminated eight and six months, respectively, before the diagnosis of chronic leukaemia was made. This is well within the period of 1.24 years stated by Hoffman and Craver (1931), from a series of 500 cases of chronic leukaemia, to be the average duration of symptoms before diagnosis is made.

\section{Treatment}

McGoldrick and Lapp found that arsenic as Fowler's solution was the treatment most commonly prescribed, but the cases they traced belonged to the era before the more recent advances in therapy were known. Irradiation, by $x$ rays or radium, of the spleen, thoracic spine, ribs, and sternum gives useful results and is still regarded by many as the most reliable treatment. Case 2 is an example of the response usually obtained. Irradiation of the pelvis is not now practised because of possible harmful effect on the foetus (Rolleston, 1930).

Edwards and Freeth (1950) treated their case satisfactorily with urethane. Case 1 made an excellent response to this drug on two occasions, not only in the lowering of the total number of leucocytes but also in the improvement of the differential count. A maintenance dose of urethane was not prescribed under out-patient conditions in view of the danger of agranulocytosis (Lancet, 1948). Li et al. (1947) treated three of their cases with radioactive phosphorus after parturition, and later also by irradiation.

Many cases require treatment for anaemia, and blood transfusion before parturition may be necessary. Undue post-partum haemorrhage also calls for transfusion, though this complication is apparently much less common than might be expected, there being only three instances of fatal haemorrhage due to acute and chronic leukaemia out of 75 cases.

\section{Conclusion and Summary}

The occurrence of pregnancy in leukaemic females is rare. The prospects for mother and child are better in the chronic than in the acute type. In all cases there is a significant incidence of premature labour, but haemorrhage, either ante- or post-partum, is not as common as may be thought. Most patients with chronic leukaemia survive pregnancy and parturition, but many collapse soon afterwards with the inevitable extension of the leukaemic process. Whether or not pregnancy should be interrupted will depend largely on the facts of the individual case, but in general it is the opinion of most writers that the shock of interruption is just as great as that of parturition, and therefore the pregnancy should be allowed to continue. Foetal mortality, though considerable, is moderate when one considers the relatively high occurrence of prematurity. Treatment of anaemia and antileukaemic measures will enhance the chance of foetal survival.

Four cases of chronic myeloid leukaemia associated with pregnancy are described. Two of the patients were probably pregnant twice during the course of the disease. Other series on the subject are summarized and shown in tabular form. The effects of leukaemia on the mother and foetus are discussed. The question of whether pregnancy has undesirable effects on leukaemia is debated. Attention is drawn to the difficulty which may arise in detecting splenomegaly in the presence of a gravid uterus.

I thank Dr. Douglas K. Adams for his advice and for permission to publish the report on Case 1 , which was treated in the Western Infirmary, Glasgow. I am indebted to the medical staff of the Glasgow Royal Maternity and Women's Hospital for access to their records.

\section{REFERENCES}

Cameron, J. C. '(1890). Amer. J. med. Sci., 100, 479

Cameron, J. C. (1890). Amer. J. med. Sct., 100, 479. Edwards, L. M., and Freeth, H. D. (1950). British Medical Journal, 2, 199. Grier, R. M., and Richter, H. A. (1939), Amer. J. Obstet. Gynec., 37, 412. Hoffman, W. (1931). Strasbourg med., 91, 611.

Hofstein,

Lancet, 1948, 1, 834. McGoldrick, J. L., and Lapp. W. A. (1943). Amer. J. Obstet, Gynec., 46. 711

Registrar-General for Scotland (1948). Annual Report. H.M.S.O

Rolleston, H. (1930). Quart. J. Med., 24, 101

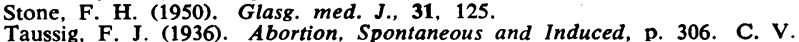
Taussig, F. J. (1936). Abortion.

Whitby, L. E. H., and Britton, C. J. C. (1946). Disorders of the Blood, 5th ed., p. 418 . Churchill, London.

Williams, J. A. (1948). Amer. J. Obstet. Gynec., 55, 967.

Wintrobe, M. M. (1951). Clinical Haematology. 3rd ed., p. 855. Kimpton, London.

In his annual report to the Swaffham Rural District Council Dr. R. N. C. McCuRDY took the opportunity to discuss the public health aspects of the work which has been done to show that cancer of the lung is associated with cigarette smoking, and in this connexion he was critical of the Minister of Health's statement in Parliament last February that the time had not yet come when the Ministry should issue public warnings against smoking. According to newspaper accounts this criticism was described as " gibing at the Minister" at a recent meeting of the Swaffham Rural District Council, which refused to accept the report. 